\title{
A Process Model for Improving Sleep through Clinical Dohsa Hou: The Subjective Experiences of Patients with Cerebral Palsy
}

\author{
Harada $\mathrm{S}^{1 *}$, Ueda $\mathrm{A}^{2}$, Morizane $\mathbf{M}^{3}$, Sato $\mathrm{S}^{1}$ and Nakano $\mathrm{K}^{5}$ \\ ${ }^{1}$ Faculty of Psychology, Iryo Sosei University, Japan \\ ${ }^{2}$ Community Psychology, Counselling, and Family Therapy Department, St. Cloud State \\ University, USA \\ ${ }^{3}$ Development Clinics of Mind and Body Eitokoro, Japan \\ ${ }^{4}$ Development Clinics of Mind and Body Maba, Japan
}

\section{Case Report}

Volume 6 Issue 1

Received Date: January 31, 2022

Published Date: February 09, 2022

DOI: $10.23880 / \mathrm{mhrij}-16000162$

*Corresponding author: Shinnosuke Harada, Faculty of Psychology, Iryo Sosei University, Fukushima, Japan; Email: harada. shinnosuke@isu.ac.jp

\section{Abstract}

People with cerebral palsy often have sleep disorders, such as difficulty falling asleep or waking up often during the night, due to their physical disabilities. The main method of treatment for this is medication. While the efficacy of pharmacotherapy has been acknowledged, it is also necessary to consider issues that have been raised in recent years concerning the side effects of sleeping pills as well as the importance of non-pharmacological approaches. This study discusses a non-pharmacological technique called Dohsa Hou or Movement Therapy in English. Dohsa Hou has for many years helped people with cerebral palsy to foster movement control and improve physical disability. There have also been reports of sleep improvement in people with cerebral palsy in recent years. In the present study, several people with cerebral palsy were chosen and interviewed about their experiences of improving their physical disabilities and sleep disorders through Dohsa Hou. The participants had to recall their experiences of practicing the therapy. The collected data were analysed using the Trajectory Equifinality Model. The results of the analysis suggested the improvement of chronic tension in the ankle, hip joint, and upper body regions as important physical experiences that lead to improved sleep in people with cerebral palsy. In addition to acquiring control to relax the body, it also showed that the acquisition of an appropriate gravitropic posture played an important role in improving the above-mentioned areas of chronic tension.

Keywords: Cerebral Palsy; Sleep Disorder; Movement Therapy; Dohsa Hou

Abbreviations: TEM: Trajectory Equifinality Model; OTP: Obligatory Transit Points; BFP: Bifurcation Points; EFP: Equifinality Point.

\section{Introduction}

People with cerebral palsy are said to be more prone to chronic physical tension due to posture issues and inadequate movement caused by their physical disabilities [1]. Such physical problems often occur even at bedtime, and it has been reported that they also have difficulty falling asleep, maintaining sleep, or achieving restful sleep due to physical tension, pain, and difficulty turning over [2]. In a study by Zuculo MG, et al. [3], the presence and severity of sleep disturbances in cerebral palsy patients were shown to have an impact not only on the quality of life of the patient but 


\section{Mental Health \& Human Resilience International Journal}

also on the quality of life of the family. Therefore, measures to deal with sleep disturbances in people with cerebral palsy are considered important supports for the individual and their family. Recently, muscle relaxants and physiotherapeutic massage techniques have been developed [4].

In this study, we focused on clinical Dohsa Hou or clinical movement therapy in English (hereinafter referred to as Dohsa Hou) as a new approach for cerebral palsy patients with sleep disorders. Dohsa Hou is a psychoeducational approach developed in Japan in the 1960s and has long been considered effective in improving the physical problems of people with cerebral palsy [1]. A recent case study suggests that the application of Dohsa Hou can function to improve sleep disorders in people with cerebral palsy [5]. Movement therapy encourages clients to self-regulate their own bodies and to self-solve their physical problems. Therefore, clients with cerebral palsy are trained in Dohsa Hou to move their disabled bodies at will and to cope with the chronic tension. Unlike other medical approaches such as medication and physical therapy, this approach leads to the client's selfdevelopment and personal growth. However, there is still a lack of knowledge about how these intrinsic experiences can be used to address the body and sleep concerns of the clients. In order to clarify the above-mentioned relationship, this study focused on the session experiences of clients receiving Dohsa Hou. By focusing on the process of the client's subjective session experiences, it is possible to understand the details of the treatment experience and process from the client's perspective. The yielded effect of Dohsa Hou can be clarified from a different perspective than through general effectiveness research using outcome measures. With the above objectives in mind, this study conducted an interview study with clients with sleep disorders caused by their cerebral palsy. The study explores the potential in addressing physical and sleep problems by Dohsa Hou, and the analysis of their internal experiences through Dohsa Hou.

\section{Methods}

\section{Participants}

There were eight participants with cerebral palsy who had experienced sleep improvement by Dohsa Hou (Table 1). All of the participants had no problems with verbal comprehension and were able to respond to interviews. The age of the participants ranged from adolescence to their $60 \mathrm{~s}$, and the type of cerebral palsy included spasticity with paralysis of the lower limbs, or all four limbs. The number of years of experience with Dohsa Hou ranged from 16 to 40 years. Four participants reported awakening during the night due to difficulty in turning over while sleeping, four had trouble falling asleep, and all eight of the participants had difficulties in consistently getting restful sleep. None of the participants had ever taken psychotropic medication such as sleeping pills, and none of the participants reported any disturbance in their daily rhythm such as day/night reversal. All of the participants answered that they did notdrinkalcohol, smoke, or consume caffeine just before bedtime, which may have interfered with sound sleep. Four of the participants had difficulty in speaking due to physical tension around their mouths, so they were interviewed with the support of their parents or guardians who were accustomed to listening to their speech. One of the participants responded in writing according to the interview guide at his own request.

\begin{tabular}{|c|c|c|c|c|c|c|c|c|}
\hline ID & Age & Diagnoses & $\begin{array}{c}\text { Years of } \\
\text { Experience } \\
\text { with } \\
\text { Dohsa-hou }\end{array}$ & $\begin{array}{c}\text { Intake of } \\
\text { Details of sleep } \\
\text { disorders }\end{array}$ & $\begin{array}{c}\text { psychotropic } \\
\text { medications } \\
\text { e.g. sleeping } \\
\text { pills }\end{array}$ & $\begin{array}{c}\text { Impairments } \\
\text { in daily rhythm } \\
\text { e.g. day and } \\
\text { night reversal }\end{array}$ & $\begin{array}{c}\text { Alcohol, } \\
\text { tobacco, } \\
\text { and caffeine } \\
\text { intake before } \\
\text { bedtime }\end{array}$ & Notes \\
\hline A & Oct-19 & $\begin{array}{c}\text { Cerebral palsy } \\
\text { (spasticity } \\
\text { type) }\end{array}$ & 16 & $\begin{array}{c}\text { Difficulties in } \\
\text { falling asleep and } \\
\text { disturbance in restful } \\
\text { sleep }\end{array}$ & N/A & N/A & N/A & $\begin{array}{c}\text { Client had } \\
\text { difficulty } \\
\text { with speech; } \\
\text { participated } \\
\text { with support }\end{array}$ \\
\hline B & $40-49$ & $\begin{array}{c}\text { Cerebral palsy } \\
\text { (spasticity } \\
\text { type) }\end{array}$ & 40 & $\begin{array}{c}\text { Difficulties in } \\
\text { falling asleep and } \\
\text { disturbance in restful } \\
\text { sleep }\end{array}$ & N/A & N/A & N/A & \\
\hline
\end{tabular}




\section{Mental Health \& Human Resilience International Journal}

\begin{tabular}{|c|c|c|c|c|c|c|c|c|}
\hline $\mathrm{C}$ & $50-59$ & $\begin{array}{c}\text { Cerebral palsy } \\
\text { (spasticity } \\
\text { type) }\end{array}$ & 40 & $\begin{array}{c}\text { Difficulties in } \\
\text { falling asleep and } \\
\text { disturbance in restful } \\
\text { sleep }\end{array}$ & $\mathrm{N} / \mathrm{A}$ & $\mathrm{N} / \mathrm{A}$ & $\mathrm{N} / \mathrm{A}$ & $\begin{array}{c}\text { Client had } \\
\text { difficulty } \\
\text { with speech; } \\
\text { answered by } \\
\text { writing }\end{array}$ \\
\hline D & $30-39$ & $\begin{array}{c}\text { Cerebral palsy } \\
\text { (spasticity } \\
\text { type) }\end{array}$ & 25 & $\begin{array}{c}\text { Difficulties in } \\
\text { falling asleep and } \\
\text { disturbance in restful } \\
\text { sleep }\end{array}$ & $\mathrm{N} / \mathrm{A}$ & $\mathrm{N} / \mathrm{A}$ & $\mathrm{N} / \mathrm{A}$ & $\begin{array}{c}\text { Client had } \\
\text { difficulty } \\
\text { with speech; } \\
\text { participated } \\
\text { with support }\end{array}$ \\
\hline $\mathrm{E}$ & $20-29$ & \begin{tabular}{|c|} 
Cerebral palsy \\
(spasticity \\
type)
\end{tabular} & 18 & $\begin{array}{l}\text { Interrupted sleep } \\
\text { due to difficulties } \\
\text { in turning over and } \\
\text { disturbances in } \\
\text { restful sleep }\end{array}$ & $\mathrm{N} / \mathrm{A}$ & N/A & $\mathrm{N} / \mathrm{A}$ & \\
\hline $\mathrm{F}$ & $30-39$ & $\begin{array}{c}\text { Cerebral palsy } \\
\text { (spasticity } \\
\text { type) }\end{array}$ & 24 & $\begin{array}{l}\text { Interrupted sleep } \\
\text { due to difficulties } \\
\text { in turning over and } \\
\text { disturbances in } \\
\text { restful sleep }\end{array}$ & $\mathrm{N} / \mathrm{A}$ & $\mathrm{N} / \mathrm{A}$ & $\mathrm{N} / \mathrm{A}$ & \\
\hline G & $30-39$ & $\begin{array}{c}\text { Cerebral palsy } \\
\text { (spasticity } \\
\text { type) }\end{array}$ & 22 & $\begin{array}{l}\text { Interrupted sleep } \\
\text { due to difficulties } \\
\text { in turning over and } \\
\text { disturbances in } \\
\text { restful sleep }\end{array}$ & $\mathrm{N} / \mathrm{A}$ & $\mathrm{N} / \mathrm{A}$ & $\mathrm{N} / \mathrm{A}$ & $\begin{array}{c}\text { Client had } \\
\text { difficulty } \\
\text { with speech; } \\
\text { participated } \\
\text { with support }\end{array}$ \\
\hline $\mathrm{H}$ & $20-29$ & $\begin{array}{c}\text { Cerebral palsy } \\
\text { (spasticity } \\
\text { type) }\end{array}$ & 19 & $\begin{array}{c}\text { Difficulties in } \\
\text { falling asleep and } \\
\text { disturbance in restful } \\
\text { sleep }\end{array}$ & $\mathrm{N} / \mathrm{A}$ & $\mathrm{N} / \mathrm{A}$ & $\mathrm{N} / \mathrm{A}$ & \\
\hline
\end{tabular}

Table1: Participants in this study List.

\section{Interview Guide}

The contents of the interview guide and the purpose of the interview are summarized in Table 2 . The interview items included questions to determine the content and frequency of sleep problems and the subjective causes of sleep problems, as well as the presence or absence of disturbances in sleep rhythms and life rhythms and the presence or absence of inappropriate sleep habits. This information is shown in Table 1. For the frequency of sleep problems, the Pittsburgh Sleep Questionnaire was used as a reference, with problems occurring more than three times a week as the criterion [6]. In addition to understanding the condition of the research participants, interview items were set to understand the process of improvement experience through Dohsa Hou, which is the purpose of this study.

\begin{tabular}{|c|c|c|}
\hline Item\# & Questions & Purpose of each question \\
\hline 1 & $\begin{array}{c}\text { Please tell us specifically about your problems with sleep. (Include } \\
\text { both past and present experiences) }\end{array}$ & Identifying the sleep problems \\
\hline 2 & How often does the problem occur (or have occurred) in a week? & $\begin{array}{c}\text { Identifying the frequency of sleep } \\
\text { problems }\end{array}$ \\
\hline 3 & On average, what time do you go to bed and what time do you wake up? & Identifying the sleeping rhythms \\
\hline 4 & $\begin{array}{c}\text { Do you have any irregularities in your daily life? If so, please tell us } \\
\text { about the situation. }\end{array}$ & Identifying disturbances in daily life \\
\hline
\end{tabular}




\section{Mental Health \& Human Resilience International Journal}

\begin{tabular}{|c|c|c|}
\hline 5 & $\begin{array}{c}\text { Do you consume caffeine, tobacco, or drink alcohol before bedtime } \\
\text { (e.g., caffeine } 6 \text { hours before bedtime, smoking and drinking } 3 \text { hours } \\
\text { before bedtime)? }\end{array}$ & Identifying inappropriate sleep habits \\
\hline 6 & $\begin{array}{c}\text { What do you think is (or was) the cause of your sleep problems? Please } \\
\text { tell us what you thinkl. }\end{array}$ & $\begin{array}{c}\text { Understanding the subjective causes of } \\
\text { sleep problems }\end{array}$ \\
\hline 7 & $\begin{array}{c}\text { Have you had any experience of solving your own sleep problems with } \\
\text { Dousa-hou? Please tell us how you solved the problem and how the } \\
\text { session was. }\end{array}$ & $\begin{array}{c}\text { Understanding the improvements using } \\
\text { the operation method }\end{array}$ \\
\hline
\end{tabular}

Table 2: List of questions in the interview guide.

\section{Research Procedures and Analysis Methods}

Research participants were recruited in Japan. The research participants and their families were contacted directly, and the interview schedule was set. The interviews were conducted by the researcher according to the interview guide described above, and the audio data of the interviews were recorded. The verbatim audio data were analysed using the Trajectory Equifinality Model (TEM). TEM analysis is a qualitative analysis method developed by Sato $\mathrm{T}$ [7] and is used to describe a group of people's life courses within irreversible time after researchers focus and organize important events and experiences. Specifically, it is a diagram of the paths formed by the obligatory transit points (OTP), the important events, bifurcation points (BFP), the branching points, and the final destination Equifinality point (EFP). In this study, one researcher with experience in TEM analysis and two researchers with more than 10 years of experience in practicing Dohsa Hou for cerebral palsy clients analysed the results.

\section{Ethical Considerations}

Before conducting this study, the research plan was submitted to the research ethics review board of the organization to which the principal researcher belongs, and approval was obtained. The purpose and procedures of this study, as well as the research presentation and writing of the paper, were explained to the research participants in writing, and their written consent was obtained. For minors participating in the research study, the same consent procedures were performed through their guardians. In addition, we refrained from describing or divulging any personal information that might identify the research participants.

\section{Results}

The results of the data analysis in this study show a process model in which persons with cerebral palsy have physical disability that leads to a sleep disorder, and how subsequent interventions with Dohsa Hou improved the sleep disorders. According to Figure 1, it was found that when daily physical difficulties became chronic, feelings of heaviness in the body, pain, and difficulty in movements all increased. This caused difficulties in falling asleep and maintaining sleep due to tensions and difficulty turning over. These sleep disturbances converged into the problem of not being able to get a restful night's sleep, which was shown to be an obligatory transit point. Afterward, it was shown that the experience of being afforded the opportunity to receive Dohsa Hou proceeded, and the specific experience path shown in Figure 2 was followed. Figure 2 shows the specific movement tasks that were performed through Dohsa Hou and the tasks that were effective in improving sleep disorders from the interviewee's perspective. Among the movement tasks that can be used as training to relax the body, the following tasks were listed: ankle relaxation task in the supine position (Figure 3), hip joints relaxation task in the supine position (Figure 4), and shoulder, back, and waist tension relaxation task (Figure 5). According to the model in Figure 2, the clients clarified the above chronic tension areas and showed the process of self-relaxation of the clarified tension themselves. In addition, by achieving self-relaxation, physical problems improved. These included a reported feeling of lightness in the body, increased ease of movement of the whole body, feelings of exhilaration, and the ability to breathe deeply. Participants showed three experiential paths after gaining the opportunity to receive Dohsa Hou; a path that begins with body relaxation task; a path with the sitting alone task; and a path with the kneeling alone task. The training to sit or kneel is a movement task that approaches posture improvement. In the sitting alone task, the assistants support the client's pelvis and help them to achieve a sitting posture with a straight back (Figure 6). The kneeling alone task, in which clients are asked to stand on their knees by themselves, requires the client to step on the floor with their kneecaps in order to maintain a posture with an elongated spine. This requires maintaining the position of the upper body and pelvis along the center of gravity line from the head to the kneecap (Figure 7). 


\section{Mental Health \& Human Resilience International Journal}
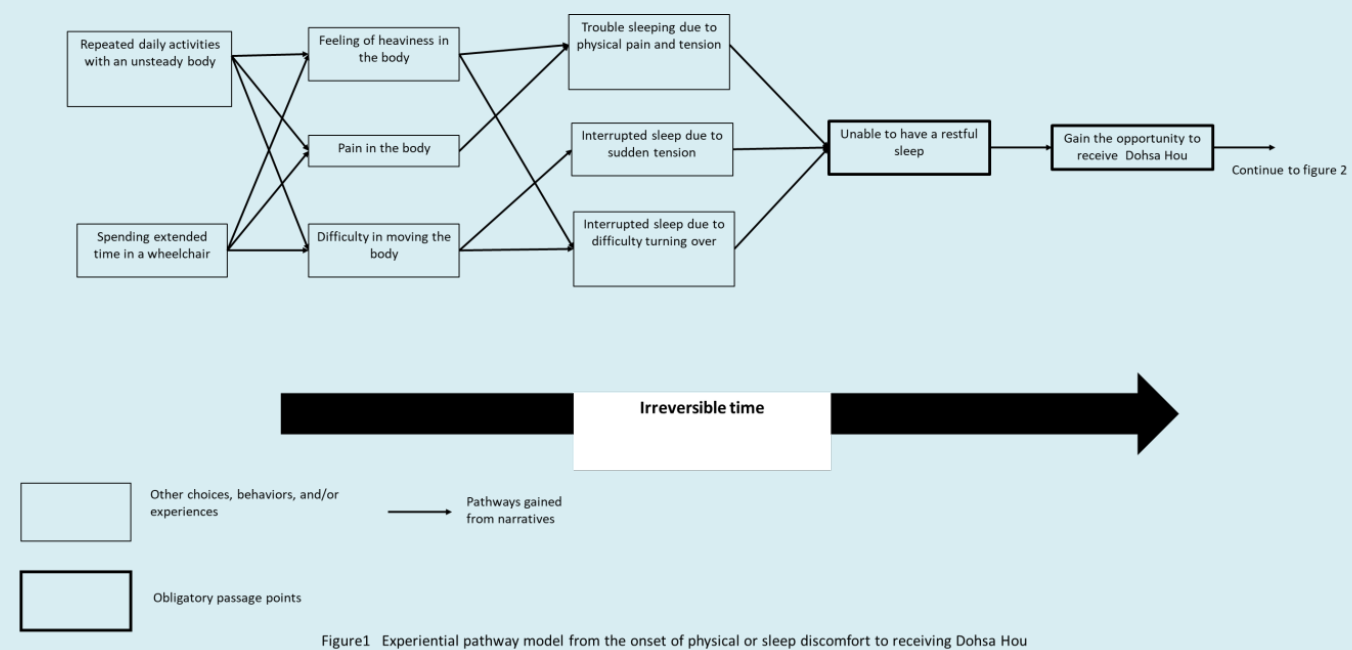

Figure 1: Experimental pathway model from the onset of physical or sleep discomfort to receiving Dohsa Hou.

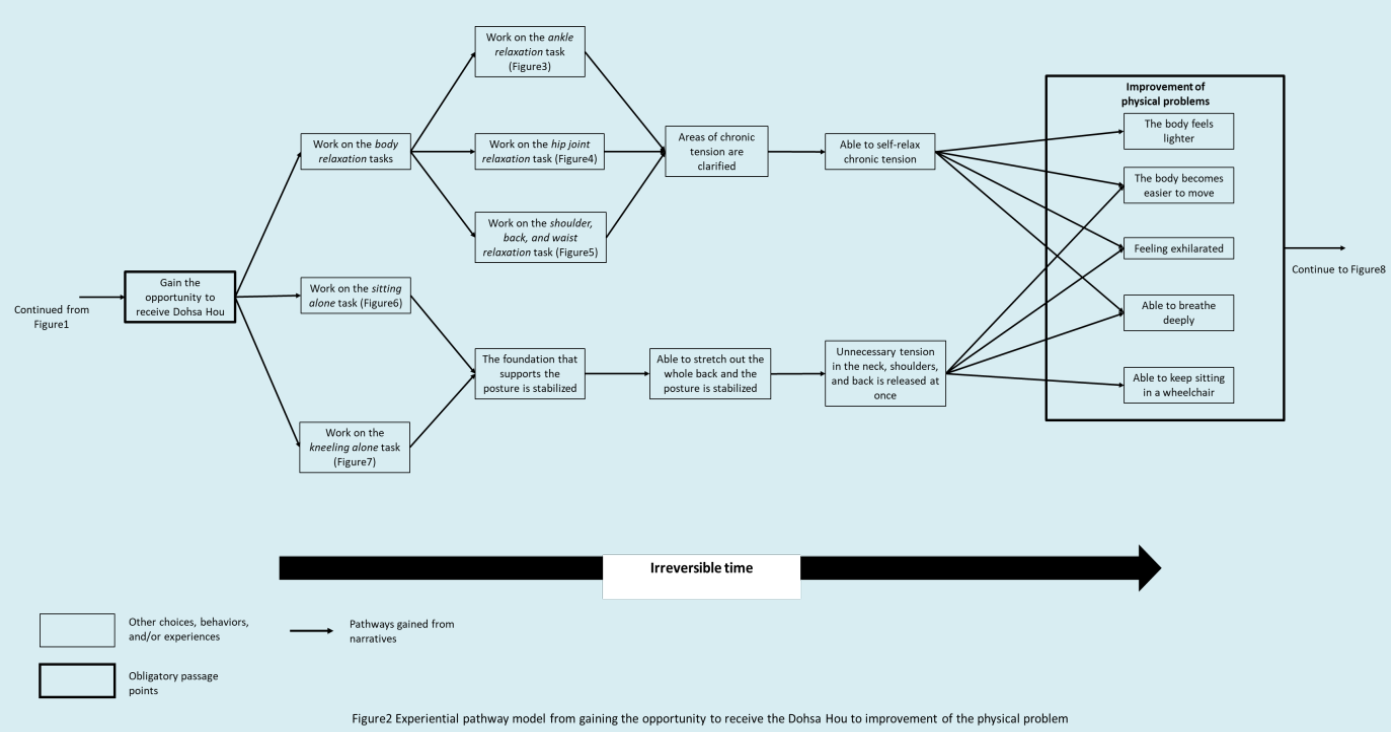

Figure 2: Experimental pathway model from gaining the opportunity to receiving Dohsa Hou to improvement of the physical problem.
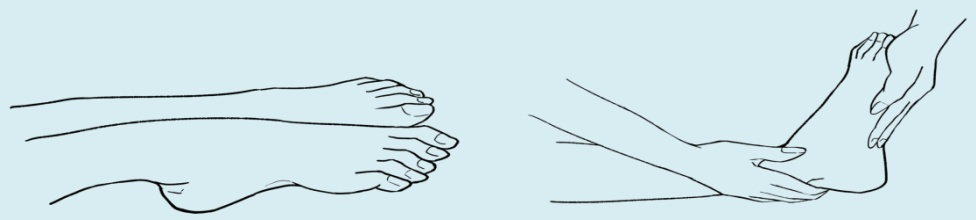

Figure3 ankle relaxation task

Figure 3: Ankle relaxation task. 

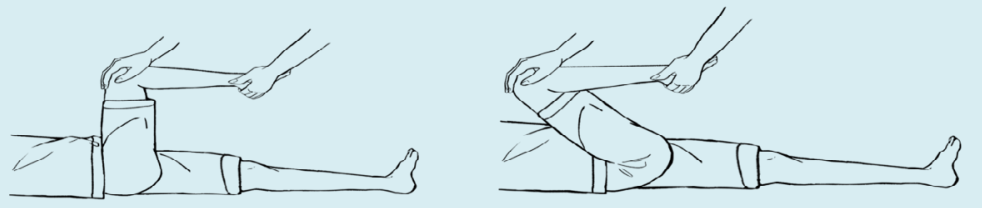

Figure4 hip joint relaxation task

Figure 4: Hip joint relaxation task.

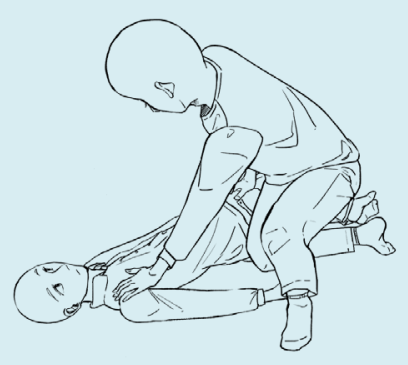

Figure5 Shoulder, back, and waist relaxation task

Figure 5: Shoulder back, and waist relaxation task.
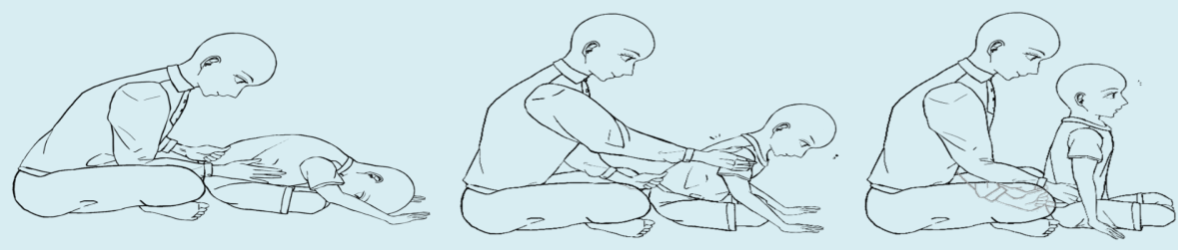

Figure6 Sitting alone task

Figure 6: Sitting alone task.
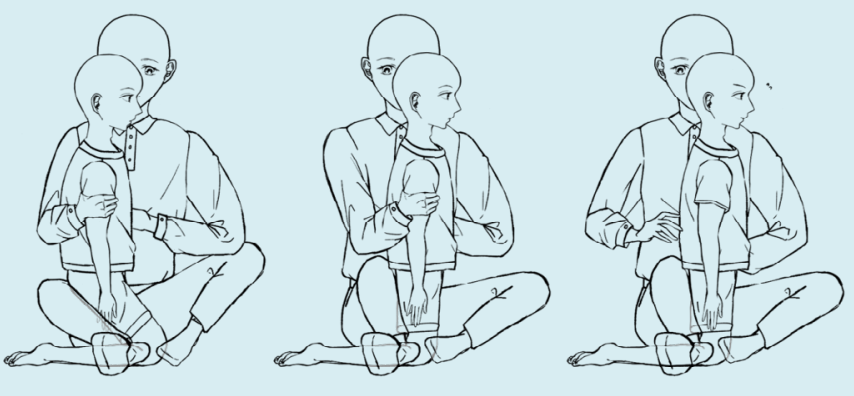

Figure7 Kneeling alone task

Figure 7: Kneeling alone task. 
Through these tasks, the clients were able to feel the stability in the foundation posture, that is, the body parts that come in contact with the floor, and showed an experience path that leads to the acquisition of a stable posture with the entire back muscles extended. When the stable posture was reached, the muscle tension that had been used to maintain the unstable posture became unnecessary, and the path of experience was shown to lead to a state of relaxation where the tension was released. The clients reported greater ease in movement, an increase in feeling refreshed, improvement in their abilities to breathe deeply and sit comfortably in a wheelchair. These five positive outcomes were grouped into one category of improvement of physical problems and understood as an obligatory transit point Figure 8 shows an experiential path from the obligatory passage point of improvement of physical problems to the Equifinality point of improvement of sleep. The clients whose physical problems were improved through Dohsa Hou experienced an improvement in the feeling of the body when lying down on the bed. Specifically, clients reported increased comfort while laying on a bed, increased comfort while sitting on a pillow, improvements in being able to stretch their entire leg comfortably, an increase in comfort in the body, and reduced pain in the lower back. In this study, these experiences were grouped into the category of improvement in the state and sensation when lying on the bed and were analysed as an obligatory passage point. After that, clients went into actual sleep and experienced an improvement in their initial problems of falling asleep, waking up in the middle of the night, and having difficulty turning over. The above experiences were grouped into one category of improvement in sleep problems and were also designated as obligatory passage points. After the above obligatory passage points, the client proceeded to the experience of achieving a restful night's sleep, which was experienced upon waking up in the morning and was shown to lead to the Equifinality point where they felt the improvement of their sleep.

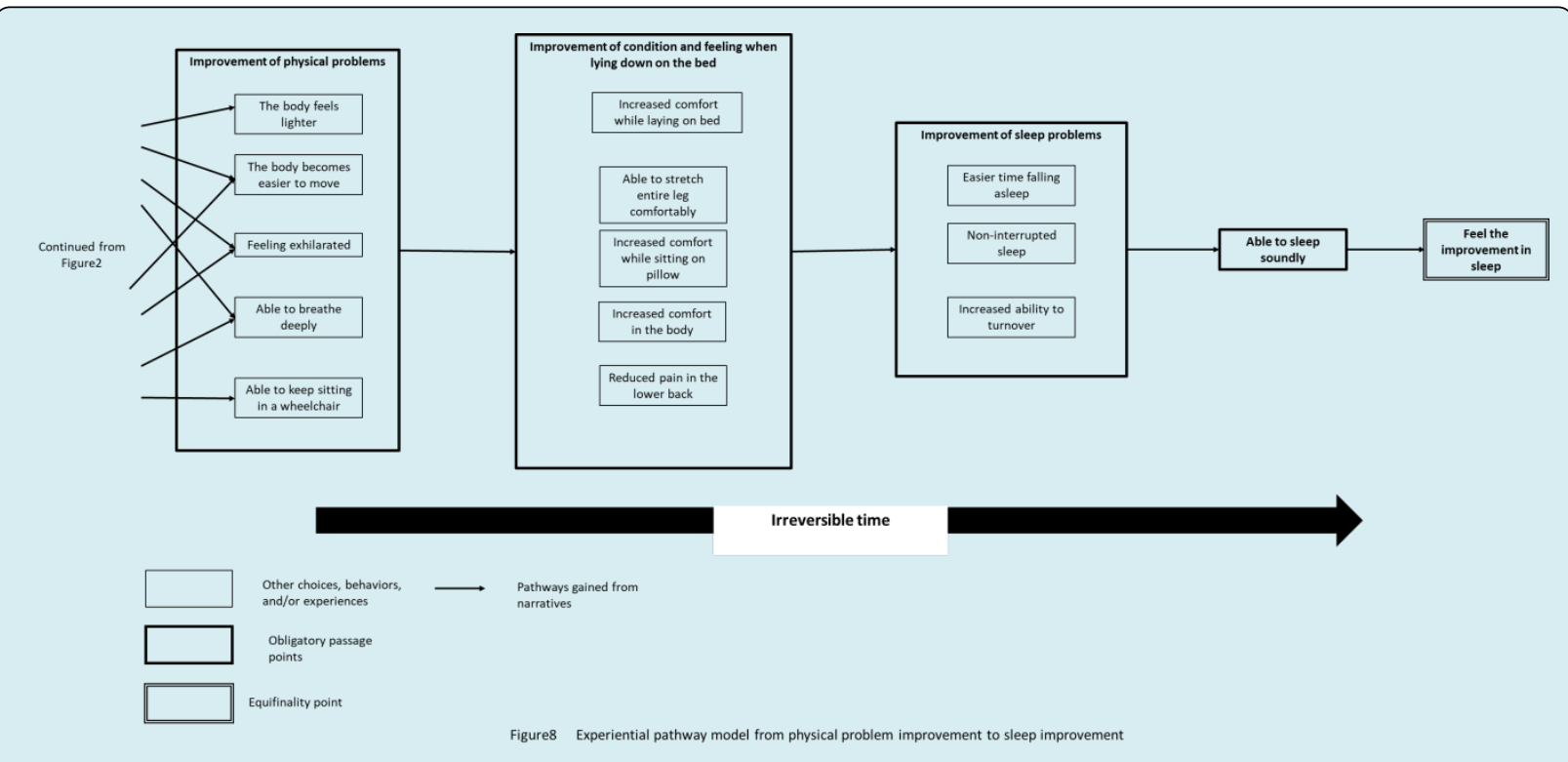

Figure 8: Experimental pathway model from physical problem improvement to sleep improvement.

\section{Discussion}

\section{Physical Problems of Cerebral Palsy Patients with Sleep Disorders and the Process of Improvement by Dohsa Hou}

In this study, the process from the occurrence of physical problems to the occurrence of sleep problems in cerebral palsy patients and the process of improvement of physical problems and sleep problems through Dohsa Hou were shown. Dutt R, et al. [2] showed that sleep disturbance in cerebral palsy patients is caused by their physical problems, and in this study, the clients experienced difficulty falling asleep or staying asleep due to pain, tension, and difficulty turning over, which may lead to a decrease in the feeling of sound sleep upon waking. In this study, an effective approach to sleep disturbance in cerebral palsy patients using Dohsa Hou was also identified. The relationship between sleep and chronic tension in the body has been demonstrated physiologically by Morin CM, et al. [8], and it is known that improvement of chronic tension around the neck and shoulders functions aids the autonomic nervous system and improves sleep. This study revealed that approaches that target both the upper body (such as the neck and shoulders) as well as to the lower body (ankles and hip joints) were effective. 


\section{Mental Health \& Human Resilience International Journal}

It was also shown that tasks that help clients acquire a stable posture were effective in improving their overall conditions. These points suggest that the chronic tension in body parts found on the upper and lower limbs may affect the sleep of the palsy patients due to their own physical disabilities. As shown, these chronic tensions are related to problems such as physical pain, sudden muscle tension, and difficulty in turning over at bedtime, and the relaxation of the above tension may lead to improvement of these physical problems. The same is true for the effectiveness of posture improvement. Because of their limb disability, people with cerebral palsy tend to assume unstable postures, which causes muscle tension in body parts that are not normally needed for posture maintenance, and this often becomes chronic [1]. It is thought that when clients develop a stable posture through Dohsa Hou, a part of the muscle tension that was previously necessary becomes unnecessary and relaxes, leading to a physical change in which the tension is released.

After identifying the improvement of the physical problems described, this study was able to show the process of how cerebral palsy clients experience improvements in sleep. Specifically, it was found that clients experienced physical improvement at the stage of lying down on the bed at night after their physical problems improved, and clients also experienced changes in physical sensations and movement, such as being able to stretch their legs. These changes may lead to the improvement in the client's abilities to fall asleep due to the decreased sensation of pain and tension that they initially had. In addition, the relaxation of the entire body is said to prevent the sudden tension that is likely to occur in people with cerebral palsy, and it is thought to have improved their sleep by addressing the tension that causes these sleep disturbances [1]. Furthermore, with chronic tension around the hip joint and waist caused by cerebral palsy, it is thought that the relaxation of chronic tension around the hip joints allows clients to stretch their legs more easily [9]. With the disappearance of pain in the waist, clients showed stronger relaxation of chronic tension around the waist and showed improvement in their ability to turn over. It is thought that these improvements in the client's ability to lay on a bed led to a favourable change in sleep, improvement in the initial problems of difficulty falling asleep and difficulty maintaining sleep, and improvement in the resulting sense of sound sleep. The present study revealed that the above experience led to the Equifinality point where the client felt the improvement of sleep.

\section{Self-Development and Self-Growth Functions of Dohsa Hou}

In this study, we focused on the function of selfdevelopment and self-growth of Dohsa Hou, which is different from conventional medical approaches. In the model presented in this study, the content and process of clients' experience of self-relaxation or self-adjustment of the posture of their own disabled body were explored. In Figure 2 , the clarification of the chronic tension area was shown before the realization of self-relaxation, and it is considered to be an experiential process of gaining realization and coping in Dohsa Hou. According to Naruse G [10], the developer of Dohsa Hou, clients realize the unconscious difficulties of movement by actually moving their own bodies, and by further working on Dohsa Hou, they gain the experience of noticing the tension in their bodies that caused the discomfort. In addition, by noticing these tensions, the clients can address the discomfort by themselves, and the above experience process is regarded as the process of the client's self-development and self-growth.

The theory of Naruse G [10] and the findings of this study are consistent with the aspect of clients' experience path through the movement task of relaxing the body, and it is thought that Dohsa Hou functions as an opportunity for self-development and self-growth for people with cerebral palsy to clarify their own physical defects and improve them through their own effort. In considering the experience path of posture improvement, clients were able to maintain the pelvic position along the center of gravity line from the head to the floor, which is the foundation of the posture, and to step on the legs, which showed the process of being able to extend the back muscles by themselves. This is considered to be an experience related to the client's self-development and self-growth because it leads to the experience of the client forming and maintaining a stable posture by their own power.

\section{Limitations of this Study and Research Prospects}

Although this study is unprecedented and challenging research that collected interviews with patients with cerebral palsy, we cannot conclude that we have completed a universal experience path model for all people with cerebral palsy due to the limited number of data. In addition, since this study was based on data collected in Japan, it is likely that the model presented in this study will change under the circumstances in different cultures and welfare education resources overseas. Based on the above points, we will continue to collect data and develop the experience pathway model presented in this study. At the same time, we will create an experience pathway model based on a psychosocial model that takes into account the cultural, welfare, and educational circumstances of each country, and conduct comparative research in each country. 


\section{Mental Health \& Human Resilience International Journal}

\section{Conclusion}

This study interviewed people with cerebral palsy, whose cases demonstrated the process by which chronic physical tension in daily situations leads to sleep disorders. The study also demonstrated the process by which these problems were improved when the movement therapy was used. According to the model presented in this study, sleep disturbance in people with cerebral palsy can be attributed to a process by which limb disabilities and the use of a wheelchair cause chronic physical tension, which leads to difficulty falling asleep and maintaining sleep during the night. In addition, it was shown that for people with cerebral palsy, the experiences of being able to relax their body and acquire a stable posture with a straight back are important to the process of improving the above-mentioned problems through the Dohsa Hou. The study demonstrated that using the Dohsa Hou described above, cerebral palsy patients were able to improve chronic tension, which leads to sleep disorders, and experienced improvement in their physical experience of going to bed as well as their sleep quality.

\section{References}

1. Harada S (2015) When Immovable Bodies Start to Move-Dohsa-hou for Children with Cerebral Palsy. In: Osamu I, Velizara C (Eds.), Introduction to Dohsa-houAn Integrated Japanese Body-Mind Therapy. Graduate School of Human Science, Osaka, Japan, pp: 19-27.

2. Dutt R, Roberts MR, Brown AC (2015) Sleep and Children with Cerebral Palsy: A Review of Current Evidence and Environmental Non-Pharmacological Interventions. Children 2(1): 78-88.
3. Zuculo MG, Knap CFC, Pinato L (2014) Correlation between sleep and quality of life in cerebral palsy. Codas, 26(6): 447-456.

4. Eek NM, Olsson K, Lindh K, Askjung B, Pahlman M, et al. (2018) Intrathecal baclofen in dyskinetic cerebral palsy: effects on function and activity. Dev Med Child Neurol 60(1): 94-99.

5. Harada S, Nagayama T, Nakano K, Morizane M (2020) The practice of dohsa-hou for sleep improvement and verification by actigraphy in trainee with cerebral palsy. The Journal of Rehabilitation Psychology 46(1): 13-24.

6. Buysse DJ, Reynolds CF, Monk HT, Berman RS, Kupfer JD (1989) The Pittsburgh Sleep Quality Index: A New Instrument for Psychiatric Practice and Research. Psychiatry Res 28(2): 193-213.

7. Sato T (2009) Starting Qualitative Research with TEM: Toward research that deals with time and process. Seishinsyobou, Tokyo, Japan, pp: 33-54.

8. Morin CM, Harui PJ, Espie CA, Spielman AJ, Buysee DJ, et al. (1999) Nonpharmacologic Treatment of Choronic Insomnia. An American Academy of Sleep Medicine Review. Sleep 22(8): 1134-1156.

9. Kibune N (2011) Developmental Support for Children with Cerebral Palsy: Toward Harmonious Development Kitaohjisyobou, Kyoto, Japan, pp: 124-129.

10. Naruse G (2014) Development of dohsa therapy: How to harmonize and utilize the mind and body. Seishinshobou, Tokyo, Japan, pp: 101-103. 